\title{
How to define and measure pedestrian traffic deaths?
}

In this brief communication we integrate and expand on two papers on pedestrian travel deaths recently published in the Journal of Transport \& Health, the Noland et al. (2017) paper on pedestrian fatality data and the importance of definitions for gathering data, and the Methorst et al. (2017) paper on the definition of 'traffic crashes'. Methorst et al. (2017) have argued to include pedestrian falls in the public realm or space in the definition of traffic crashes. Even if we use the current definition, which excludes pedestrian injuries without motor vehicle involvement, pedestrian fatalities account for $22 \%$ of all traffic deaths worldwide, ranging from 13\% in South-East Asia to 22\% in the Americas, 26\% in Europe and $39 \%$ in Africa (WHO, 2015). Policies to improve pedestrian safety are important to reduce the burden of deaths and injuries, but also to encourage people to participate in active transport and enjoy the sizable health benefits of physical activity (Kelly et al., 2014). This starts with gathering data to understand the problem of pedestrian safety and to inform policies (Noland et al., 2017).

Definitions are important to frame problems under study and as a basis for gathering data, throwing excluded aspects in the shadow and outside of official statistics (Noland et al., 2017; Weiss, 1989). With regard to pedestrian deaths, three concepts need to be defined adequately: 'Pedestrian', 'Public Space', and 'Traffic crash'. An important requirement is that the definition provides a way of operationally measuring a phenomenon in a specific context. Moreover, we need to understand pedestrian falls in the public space to develop transport policy and to be able to evaluate interventions.

There are a variety of ways to define the concept of being a pedestrian, for instance the National Highway Traffic Safety Administration (NHTSA) and United States Department of Transport (USDOT) definitions (Noland et al., 2017). In the NHTSA definition, a pedestrian is any person on foot, walking, running, hiking, sitting or lying down (National Highway Traffic Safety Administration, 2014). By applying this definition on collisions with motor vehicles, NHTSA centred its definition on the collision between a pedestrian and a motor vehicle and not on the overall pedestrian risks. In the USDOT definition, a pedestrian is any person who is not an occupant of a motor vehicle or pedal cyclist, regardless of their actions (USDOT (2012), p. 86). The latter definition includes persons using wheelchairs, skates and a variety of personal movers like mobility scooters and Segways, which generally use pedestrian facilities and of which users have to obey the same traffic rules as other persons on foot. We suggest adopting the most simple and clear definition: 'all persons on foot, walking, hiking, sitting or lying down'. As mobility and safety characteristics and requirements of personal movers may differ substantially from actual pedestrians, it would be better to treat them as a separate mode.

In their paper, Noland and colleagues' (2017), restrict the definition to pedestrian safety on public highways, excluding parks, special foot paths and privately owned parking areas. The latter indeed falls outside public jurisdiction, but public parks and footpaths are public spaces and therefore should be included in public policy making, planning, management and control. In our article (Methorst et al., 2017) we pleaded for widening the perspective to public space, i.e. all publicly owned and managed space.

Pedestrian falls are currently excluded from the definition of traffic crashes (a vehicle is required to classify as traffic crash) and are a growing problem for western societies where about half of all pedestrian deaths and the large majority of non-fatal injuries are due to pedestrian falls in public spaces (Methorst et al., 2017). Road factors such as kerb heights and road surface friction contribute to a substantial share of pedestrian falls (Lai et al., 2011; Nyman et al., 2013). Road safety visions such as Vision Zero ascribe 'forward-looking 
responsibility' to system designers such as public space authorities (Fahlquist, 2006). Methorst et al. (2017) argue that they can only carry this responsibility for pedestrians if pedestrian falls are added to the definition of traffic crashes and maybe also call these incidents 'travel injuries' or 'traffic crashes and falls'.

It is important to bear in mind that definitions are a necessary but insufficient condition to achieve reliable and comprehensive data collection (Noland et al., 2017). This is also shown by the experiences with cyclist falls, also called single-bicycle crashes. It is well known that the police hardly record non-fatal bicycle crashes without motor vehicles being involved (see e.g. Langley et al., 2003). One important reason is that in many cases the police are not drawn in to record such single crashes. Only recently, it appeared from comparing police statistics with causes of deaths statistics that a similar problem seems to apply to fatal bicycle crashes (Schepers et al., 2016). Table 1 shows causes of death statistics in the Netherlands contained three times as many deaths following crashes without motor vehicles compared with police statistics. "Statistics Netherlands" estimates numbers of road crash deaths by linking (incomplete) police statistics, court files and cause of death forms filled out by a coroner to exclude suicides and crashes occurring outside public roads (SWOV, 2015), yielding an estimate of 186 cyclist deaths in 2010-2014, almost exactly matching the 187 cyclist deaths recorded in causes of death statistics. This suggests that the quality of causes of death statistics is fairly good. Comparisons between recorded deaths between alternative sources are rare, but a similar difference between police and causes of death statistics is present in Flanders (Agentschap Zorg en Gezondheid, 2017; Statistics Belgium, 2017). More detailed studies of cyclists admitted to hospital following crashes without motor vehicles and recorded through 9th version of the International Classification of Diseases (ICD-9) in the Netherlands and Flanders suggest that between 3\% and $8 \%$ did not occur on public roads (Nuyttens, 2013). This is corroberated by questionaire (e.g. for the Netherlands Schepers, 2008), but the percentage may be somewhat higher in other countries such as Australia with more recreational cycling where for instance off-road mountain biking injuries may be more frequent (Heesch et al., 2011).

Table 1 Cyclist deaths per year in Causes of Death Statistics (CS) and police statistics (PS) in 2010-2014 in The Netherlands (Statistics Netherlands, 2015; SWOV, 2017)

\begin{tabular}{l|l|lll|}
\hline Crash type & ICD-10 codes causes & \multicolumn{4}{|c|}{ Netherlands } \\
\hline of death statistics & CDS & CDS* & PS \\
\hline With motor vehicles & V12-V16 & 112 & 116 & 111 \\
Without motor vehicles & V10, V11, V16-V18 & 69 & 71 & 23 \\
Unspecified & V19 & 6 & & \\
\hline Total & & 187 & 187 & 134 \\
\hline
\end{tabular}

* Unspecified assigned to with or without motor vehicles

Noland et al. (2017) examined police reported pedestrian deaths assuming the current definition, i.e. pedestrian-motor vehicle crashes. They found several issues, e.g. 14\% of fatal crashes did not involve a traveling pedestrian, e.g. a motorist who was killed standing outside a disabled vehicle. The database also included a few intentional homicides and casualties who were actually in wheelchairs. Notwithstanding the importance of reliable crash reporting by the police (e.g. to correctly report travel mode and exclude homicides and suicides), police reported data are still an excellent source to understand pedestrian-motor vehicle crashes compared with the complete lack of data for public space authorities on pedestrian falls.

Notwithstanding possible differences between countries, the aforementioned experiences with the recording of cyclist falls demonstrate that, even fatal falls may not be 
included in police statistics, and are even strongly underreported in some countries. This is worrying, as data are needed for this emerging problem and most (local) authorities only have access to police statistics. At least in western societies, it is to be expected that the problem of pedestrian-motor vehicle crashes will further decrease thanks to safer vehicles (for instance new systems such as automated braking and pedestrian airbags on car bonnets), while an ageing society is likely to contribute to a continuing trend of increasing number of serious and fatal pedestrian falls. To increase insight into these falls, not only do we have to include this issue in the definition of 'traffic crashes', we also need to seek other data sources, e.g. insurance companies, ambulance services.

Experiences with cyclist falls suggest that hospital data (including data from both Emergency Departments and hospital admissions and discharges) and causes of death statistics (based on death certificates and post-mortems by medical examiners) are promising. An advantage of these sources is that generally the International Classification of Diseases (ICD) is used to record data. Unfortunately, the three-digit ICD codes in version 10 are insufficient for pedestrian falls. Pedestrian falls occur both indoors and outdoors. The location is likely to be sufficiently described by four-digit ICD-10 codes (codes W00-W05, W10, W17-W19 and X59 with the fourth digit code 'Place of occurrence' is '4' for 'Street and highway' (Mindell et al. 2012). Unfortunately, other types of public spaces, like public parks and footpaths, are not specified). Research into the accuracy of this data is needed and it may be a challenge to identify crashes in public spaces and to distinguish these from other outdoor falls such as in gardens.

To summarize, we recommend considering changing the definition of 'traffic crashes' in the following ways: "any vehicle crash or pedestrian fall occurring in public spaces." We suggest that such a definition will inform public space authorities and help them take their responsibility to take all reasonable preventive measures. Police statistics have advantages such as detailed crash locations and disadvantages such as insufficient reliability for some crash characteristics. Nevertheless, this source is still by far the most useful and complete for severe and fatal pedestrian-motor vehicle crashes. We therefore recommend investment in collection of data on pedestrian falls using hospital data and causes of deaths statistics. ICD seems an adequate and internally available starting point.

\section{References}

Agentschap Zorg en Gezondheid, 2017. Doodsoorzakenstatistiek 2010-2014 https://www.zorg-en-gezondheid.be/ (accessed 15-05-2017)

Fahlquist, J.N., 2006. Responsibility ascriptions and vision zero. Accident Analysis and Prevention 38, 1113-1118.

Heesch, K. C., Garrard, J., \& Sahlqvist, S., 2011. Incidence, severity and correlates of bicycling injuries in a sample of cyclists in Queensland, Australia. Accident Analysis \& Prevention, 43(6), 2085-2092.

Kelly, P., Kahlmeier, S., Götschi, T., Orsini, N., Richards, J., Roberts, N., Scarborough, P., Foster, C., 2014. Systematic review and meta-analysis of reduction in all-cause mortality from walking and cycling and shape of dose response relationship. International Journal of Behavioral Nutrition and Physical Activity 11, 132. 
Lai, P.-C., Wong, W.-C., Low, C.-T., Wong, M., Chan, M.-H., 2011. A small-area study of environmental risk assessment of outdoor falls. Journal of Medical Systems 35, 1543-1552.

Langley, J.D., Dow, N., Stephenson, S., Kypri, K., 2003. Missing cyclists. Injury prevention 9, 376-379.

Methorst, R., Schepers, P., Christie, N., Dijst, M., Risser, R., Sauter, D., Van Wee, B., 2017. 'Pedestrian falls' as necessary addition to the current definition of traffic crashes for improved public health policies. Journal of Transport and Health 2017 vol X, pp XXX-XXX (Elsevier team to add the correct citation when these are known)'

http://dx.doi.org/10.1016/j.jth.2017.02.005.

Noland, R. B., Sinclair, J. A., Klein, N. J., Brown, C., 2017. How good is pedestrian fatality data? Journal of Transport \& Health. vol X, pp XXX-XXX (Elsevier team to add the correct citation when these are known)' https://doi.org/10.1016/i.jth.2017.04.006

Mindell, J. S., Leslie, D., \& Wardlaw, M. (2012). Exposure-based,'like-for-like'assessment of road safety by travel mode using routine health data. PloS one, 7(12), e50606.

Nuyttens, N., 2013. Onderregistratie van Verkeersslachtoffers (Underreporting of Road Crash Victims). Brussels: Belgisch Instituut voor de Verkeersveiligheid (BIVV).

Nyman, S., Ballinger, C., Phillips, J., Newton, R., 2013. Characteristics of outdoor falls among older people: A qualitative study. BMC Geriatry 13, 125.

Reurings, 2010. Ernstig verkeersgewonden in Nederland in 1993-2008; R-2010-15 (Serious road injuries in the Netherlands in 1993-2008). Leidschendam: SWOV Institute for Road Safety Research.

Schepers, P., Stipdonk, H., Methorst, R., Olivier, J., 2016. Bicycle fatalities: trends in crashes with and without motor vehicles in The Netherlands. Transportation research part F. vol X, pp XXX-XXX (Elsevier team to add the correct citation when these are known)'https://doi.org/10.1016/j.trf.2016.05.007

Statistics Belgium (2017). FOD Mobiliteit en Vervoer. https://bestat.economie.fgov.be/bestat/crosstable.xhtml?view=9090f429-32f6-40c3-a68504cef7b6b0f1 (accessed 15-10-2015)

Statistics Netherlands (2015). Statline http://statline.cbs.nl/Statweb/ (accessed 15-10-2015)

SWOV (2017). Cognos http://www.swov.nl (accessed 15-05-2017)

SWOV (2015). Factsheet road fatalities in the Netherlands. The Hague: SWOV Institute for Road Safety Research. 
187 Weiss, J., 1989. The powers of problem definition: The case of government paperwork.

188 Policy Sciences 22, 97-121.

190 WHO, 2015. Global Status Reporton Road Safety 2015. World Health Organization, Geneva.

192 WHO, 2016. International Statistical Classification of Diseases and Related Health Problems 193 10th Revision (ICD-10)-WHO Version for 2016.

194 http://apps.who.int/classifications/icd10/browse/2016/en\#/XX (accessed 05-05-2017) 
How to define and measure pedestrian traffic deaths?

Rob Methorst, ${ }^{a}$ Paul Schepers, ${ }^{b}$ Nicola Christie, ${ }^{\mathrm{c}}$ Bas de Geus ${ }^{\mathrm{d}}$

a external PhD candidate Delft University of Technology, The Netherlands

b Department of Human Geography and Spatial Planning, Faculty of Geosciences, Utrecht University, Heidelberglaan 2, Utrecht 3584 CS, The Netherlands

c Department of Civil, Environment \& Geomatic Engineering, UCL Transport Institute, University College of London, Gower Street, London WC1E 6BT, United Kingdom Correspondence to Rob Methorst (email: rob.methorst@telfort.nl)

d Human Physiology Research Group, Vrije Universiteit Brussel, Pleinlaan 2, 1050 Brussels, Belgium

corresponding author: Rob Methorst, e-mail: rob.methorst@telfort.nl 


\section{How to define and measure pedestrian traffic deaths?}

In this brief communication we integrate and expand on two papers on pedestrian travel deaths recently published in the Journal of Transport \& Health, the Noland et al. (2017) paper on pedestrian fatality data and the importance of definitions for gathering data, and the Methorst et al. (2017) paper on the definition of 'traffic crashes'. Methorst et al. (2017) have argued to include pedestrian falls in the public realm or space in the definition of traffic crashes. Even if we use the current definition, which excludes pedestrian injuries without motor vehicle involvement, pedestrian fatalities account for $22 \%$ of all traffic deaths worldwide, ranging from 13\% in South-East Asia to 22\% in the Americas, 26\% in Europe and $39 \%$ in Africa (WHO, 2015). Policies to improve pedestrian safety are important to reduce the burden of deaths and injuries, but also to encourage people to participate in active transport and enjoy the sizable health benefits of physical activity (Kelly et al., 2014). This starts with gathering data to understand the problem of pedestrian safety and to inform policies (Noland et al., 2017).

Definitions are important to frame problems under study and as a basis for gathering data, throwing excluded aspects in the shadow and outside of official statistics (Noland et al., 2017; Weiss, 1989). With regard to pedestrian deaths, three concepts need to be defined adequately: 'Pedestrian', 'Public Space', and 'Traffic crash'. An important requirement is that the definition provides a way of operationally measuring a phenomenon in a specific context. Moreover, we need to understand pedestrian falls in the public space to develop transport policy and to be able to evaluate interventions.

There are a variety of ways to define the concept of being a pedestrian, for instance the National Highway Traffic Safety Administration (NHTSA) and United States Department of Transport (USDOT) definitions (Noland et al., 2017). In the NHTSA definition, a pedestrian is any person on foot, walking, running, hiking, sitting or lying down (National Highway Traffic Safety Administration, 2014). By applying this definition on collisions with motor vehicles, NHTSA centred its definition on the collision between a pedestrian and a motor vehicle and not on the overall pedestrian risks. In the USDOT definition, a pedestrian is any person who is not an occupant of a motor vehicle or pedal cyclist, regardless of their actions (USDOT (2012), p. 86). The latter definition includes persons using wheelchairs, skates and a variety of personal movers like mobility scooters and Segways, which generally use pedestrian facilities and of which users have to obey the same traffic rules as other persons on foot. We suggest adopting the most simple and clear definition: 'all persons on foot, walking, hiking, sitting or lying down'. As mobility and safety characteristics and requirements of personal movers may differ substantially from actual pedestrians, it would be better to treat them as a separate mode.

In their paper, Noland and colleagues' (2017), restrict the definition to pedestrian safety on public highways, excluding parks, special foot paths and privately owned parking areas. The latter indeed falls outside public jurisdiction, but public parks and footpaths are public spaces and therefore should be included in public policy making, planning, management and control. In our article (Methorst et al., 2017) we pleaded for widening the perspective to public space, i.e. all publicly owned and managed space.

Pedestrian falls are currently excluded from the definition of traffic crashes (a vehicle is required to classify as traffic crash) and are a growing problem for western societies where about half of all pedestrian deaths and the large majority of non-fatal injuries are due to pedestrian falls in public spaces (Methorst et al., 2017). Road factors such as kerb heights and road surface friction contribute to a substantial share of pedestrian falls (Lai et al., 2011; Nyman et al., 2013). Road safety visions such as Vision Zero ascribe 'forward-looking 
responsibility' to system designers such as public space authorities (Fahlquist, 2006). Methorst et al. (2017) argue that they can only carry this responsibility for pedestrians if pedestrian falls are added to the definition of traffic crashes and maybe also call these incidents 'travel injuries' or 'traffic crashes and falls'.

It is important to bear in mind that definitions are a necessary but insufficient condition to achieve reliable and comprehensive data collection (Noland et al., 2017). This is also shown by the experiences with cyclist falls, also called single-bicycle crashes. It is well known that the police hardly record non-fatal bicycle crashes without motor vehicles being involved (see e.g. Langley et al., 2003). One important reason is that in many cases the police are not drawn in to record such single crashes. Only recently, it appeared from comparing police statistics with causes of deaths statistics that a similar problem seems to apply to fatal bicycle crashes (Schepers et al., 2016). Table 1 shows causes of death statistics in the Netherlands contained three times as many deaths following crashes without motor vehicles compared with police statistics. "Statistics Netherlands" estimates numbers of road crash deaths by linking (incomplete) police statistics, court files and cause of death forms filled out by a coroner to exclude suicides and crashes occurring outside public roads (SWOV, 2015), yielding an estimate of 186 cyclist deaths in 2010-2014, almost exactly matching the 187 cyclist deaths recorded in causes of death statistics. This suggests that the quality of causes of death statistics is fairly good. Comparisons between recorded deaths between alternative sources are rare, but a similar difference between police and causes of death statistics is present in Flanders (Agentschap Zorg en Gezondheid, 2017; Statistics Belgium, 2017). More detailed studies of cyclists admitted to hospital following crashes without motor vehicles and recorded through 9th version of the International Classification of Diseases (ICD-9) in the Netherlands and Flanders suggest that between $3 \%$ and $8 \%$ did not occur on public roads (Nuyttens, 2013). This is corroberated by questionaire (e.g. for the Netherlands Schepers, 2008), but the percentage may be somewhat higher in other countries such as Australia with more recreational cycling where for instance off-road mountain biking injuries may be more frequent (Heesch et al., 2011).

Table 1 Cyclist deaths per year in Causes of Death Statistics (CS) and police statistics (PS) in 2010-2014 in The Netherlands (Statistics Netherlands, 2015; SWOV, 2017)

\begin{tabular}{l|l|lll|}
\hline Crash type & ICD-10 codes causes & \multicolumn{4}{|c|}{ Netherlands } \\
\hline of death statistics & CDS & CDS* & PS \\
\hline With motor vehicles & V12-V16 & 112 & 116 & 111 \\
Without motor vehicles & V10, V11, V16-V18 & 69 & 71 & 23 \\
Unspecified & V19 & 6 & & \\
\hline Total & & 187 & 187 & 134 \\
\hline
\end{tabular}

* Unspecified assigned to with or without motor vehicles

Noland et al. (2017) examined police reported pedestrian deaths assuming the current definition, i.e. pedestrian-motor vehicle crashes. They found several issues, e.g. $14 \%$ of fatal crashes did not involve a traveling pedestrian, e.g. a motorist who was killed standing outside a disabled vehicle. The database also included a few intentional homicides and casualties who were actually in wheelchairs. Notwithstanding the importance of reliable crash reporting by the police (e.g. to correctly report travel mode and exclude homicides and suicides), police reported data are still an excellent source to understand pedestrian-motor vehicle crashes compared with the complete lack of data for public space authorities on pedestrian falls.

Notwithstanding possible differences between countries, the aforementioned experiences with the recording of cyclist falls demonstrate that, even fatal falls may not be 
included in police statistics, and are even strongly underreported in some countries. This is worrying, as data are needed for this emerging problem and most (local) authorities only have access to police statistics. At least in western societies, it is to be expected that the problem of pedestrian-motor vehicle crashes will further decrease thanks to safer vehicles (for instance new systems such as automated braking and pedestrian airbags on car bonnets), while an ageing society is likely to contribute to a continuing trend of increasing number of serious and fatal pedestrian falls. To increase insight into these falls, not only do we have to include this issue in the definition of 'traffic crashes', we also need to seek other data sources, e.g. insurance companies, ambulance services.

Experiences with cyclist falls suggest that hospital data (including data from both Emergency Departments and hospital admissions and discharges) and causes of death statistics (based on death certificates and post-mortems by medical examiners) are promising. An advantage of these sources is that generally the International Classification of Diseases (ICD) is used to record data. Unfortunately, the three-digit ICD codes in version 10 are insufficient for pedestrian falls. Pedestrian falls occur both indoors and outdoors. The location is likely to be sufficiently described by four-digit ICD-10 codes (codes W00-W05, W10, W17-W19 and X59 with the fourth digit code 'Place of occurrence' is '4' for 'Street and highway' (Mindell et al. 2012). Unfortunately, other types of public spaces, like public parks and footpaths, are not specified). Research into the accuracy of this data is needed and it may be a challenge to identify crashes in public spaces and to distinguish these from other outdoor falls such as in gardens.

To summarize, we recommend considering changing the definition of 'traffic crashes' in the following ways: "any vehicle crash or pedestrian fall occurring in public spaces." We suggest that such a definition will inform public space authorities and help them take their responsibility to take all reasonable preventive measures. Police statistics have advantages such as detailed crash locations and disadvantages such as insufficient reliability for some crash characteristics. Nevertheless, this source is still by far the most useful and complete for severe and fatal pedestrian-motor vehicle crashes. We therefore recommend investment in collection of data on pedestrian falls using hospital data and causes of deaths statistics. ICD seems an adequate and internally available starting point.

\section{References}

Agentschap Zorg en Gezondheid, 2017. Doodsoorzakenstatistiek 2010-2014 https://www.zorg-en-gezondheid.be/ (accessed 15-05-2017)

Fahlquist, J.N., 2006. Responsibility ascriptions and vision zero. Accident Analysis and Prevention 38, 1113-1118.

Heesch, K. C., Garrard, J., \& Sahlqvist, S., 2011. Incidence, severity and correlates of bicycling injuries in a sample of cyclists in Queensland, Australia. Accident Analysis \& Prevention, 43(6), 2085-2092.

Kelly, P., Kahlmeier, S., Götschi, T., Orsini, N., Richards, J., Roberts, N., Scarborough, P., Foster, C., 2014. Systematic review and meta-analysis of reduction in all-cause mortality from walking and cycling and shape of dose response relationship. International Journal of Behavioral Nutrition and Physical Activity 11, 132. 
Lai, P.-C., Wong, W.-C., Low, C.-T., Wong, M., Chan, M.-H., 2011. A small-area study of environmental risk assessment of outdoor falls. Journal of Medical Systems 35, 1543-1552.

Langley, J.D., Dow, N., Stephenson, S., Kypri, K., 2003. Missing cyclists. Injury prevention 9, 376-379.

Methorst, R., Schepers, P., Christie, N., Dijst, M., Risser, R., Sauter, D., Van Wee, B., 2017. 'Pedestrian falls' as necessary addition to the current definition of traffic crashes for improved public health policies. Journal of Transport and Health 2017 vol X, pp XXX-XXX (Elsevier team to add the correct citation when these are known)'

http://dx.doi.org/10.1016/j.jth.2017.02.005.

Noland, R. B., Sinclair, J. A., Klein, N. J., Brown, C., 2017. How good is pedestrian fatality data? Journal of Transport \& Health. vol X, pp XXX-XXX (Elsevier team to add the correct citation when these are known)' https://doi.org/10.1016/i.jth.2017.04.006

Mindell, J. S., Leslie, D., \& Wardlaw, M. (2012). Exposure-based,'like-for-like'assessment of road safety by travel mode using routine health data. PloS one, 7(12), e50606.

Nuyttens, N., 2013. Onderregistratie van Verkeersslachtoffers (Underreporting of Road Crash Victims). Brussels: Belgisch Instituut voor de Verkeersveiligheid (BIVV).

Nyman, S., Ballinger, C., Phillips, J., Newton, R., 2013. Characteristics of outdoor falls among older people: A qualitative study. BMC Geriatry 13, 125.

Reurings, 2010. Ernstig verkeersgewonden in Nederland in 1993-2008; R-2010-15 (Serious road injuries in the Netherlands in 1993-2008). Leidschendam: SWOV Institute for Road Safety Research.

Schepers, P., Stipdonk, H., Methorst, R., Olivier, J., 2016. Bicycle fatalities: trends in crashes with and without motor vehicles in The Netherlands. Transportation research part F. vol X, pp XXX-XXX (Elsevier team to add the correct citation when these are known)'https://doi.org/10.1016/j.trf.2016.05.007

Statistics Belgium (2017). FOD Mobiliteit en Vervoer. https://bestat.economie.fgov.be/bestat/crosstable.xhtml?view=9090f429-32f6-40c3-a68504cef7b6b0f1 (accessed 15-10-2015)

Statistics Netherlands (2015). Statline http://statline.cbs.nl/Statweb/ (accessed 15-10-2015)

SWOV (2017). Cognos http://www.swov.nl (accessed 15-05-2017)

SWOV (2015). Factsheet road fatalities in the Netherlands. The Hague: SWOV Institute for Road Safety Research. 
187 Weiss, J., 1989. The powers of problem definition: The case of government paperwork.

188 Policy Sciences 22, 97-121.

190 WHO, 2015. Global Status Reporton Road Safety 2015. World Health Organization, Geneva.

192 WHO, 2016. International Statistical Classification of Diseases and Related Health Problems 193 10th Revision (ICD-10)-WHO Version for 2016.

194 http://apps.who.int/classifications/icd10/browse/2016/en\#/XX (accessed 05-05-2017) 